\title{
A Survey to Assess the Awareness and Acceptance of Dental Implants among Patients Seeking Prosthodontic Rehabilitation
}

\author{
Akshata Rao ${ }^{1}$, Chethan Hegde ${ }^{2}$ \\ 1,2 Department of Prosthodontics and Crown \& Bridge, AB Shetty Memorial Institute of Dental Sciences, \\ Nitte (Deemed to Be University), Derlakatte, Mangalore, Karnataka, India.
}

\section{ABSTRACT}

\section{BACKGROUND}

In this study, we wanted to assess the awareness, knowledge, and acceptance of dental implants as a treatment modality among patients visiting A.B Shetty Memorial Institute of Dental Sciences, Mangalore, Karnataka.

\section{METHODS}

A cross-sectional survey was conducted among 100 patients visiting A.B. Shetty Memorial Institute of Dental Sciences, Mangalore, using a self-explanatory questionnaire.

\section{RESULTS}

The results of this survey indicate that $51 \%$ of the patients were not aware of implant therapy as a treatment option for replacing missing teeth and $44.9 \%$ were aware about it. $38 \%$ of the patients received information about implants from dentist and $38 \%$ of them received from books / magazine / internet. $44.3 \%$ of the patients were willing to undergo implant therapy as a treatment option if needed but $25.8 \%$ of the patients were not willing. $29.9 \%$ of them were open to the idea of implants but were not sure. $58.8 \%$ of the patients rated implant treatment as not affordable and $41.2 \%$ rated it as affordable. The most common reason listed for not opting implant treatment was found to be the cost of the treatment (45.1\%), $27.5 \%$ of the patients were not clear about the procedure and $11.8 \%$ of them stated long treatment time as the disadvantage of implant therapy.

\section{CONCLUSIONS}

This study revealed a low level of awareness (44.9\%) among the patients regarding dental implants although, $44.3 \%$ showed a positive attitude towards implant therapy. The study also revealed the need for further studies involving the general population as majority of the patients in this study were from a low socio-economic background.

\section{KEY WORDS}

Implant Supported Prosthesis, Awareness, Acceptance, Prosthodontic Rehabilitation
Corresponding Author: Dr. Chethan Hegde, $A B$ Shetty Memorial Institute of Dental Sciences, Nitte (Deemed to Be University), Derlakatte, Mangalore, Karnataka, India. E-mail: hegdechethan@yahoo.co.in

DOI: $10.14260 / j e m d s / 2021 / 310$

How to Cite This Article:

Rao A, Hegde C. A survey to assess the awareness and acceptance of dental implants among patients seeking prosthodontic rehabilitation. J Evolution Med Dent Sci 2021;10(20):1479-1482, DOI: 10.14260/jemds/2021/310

Submission 02-12-2020,

Peer Review 06-03-2021,

Acceptance 12-03-2021,

Published 17-05-2021.

Copyright (C) 2021 Akshata Rao et al. This is an open access article distributed under Creative Commons Attribution License [Attribution 4.0 International (CC BY 4.0)] 


\section{BACKGROUND}

The aim of modern dentistry is to restore the patient's teeth to normal function, aesthetics, speech, and health. ${ }^{1}$ The loss of natural teeth is associated with functional, cosmetic as well as psychological morbidities. Rehabilitation of the lost natural teeth is usually achieved using dentures and fixed bridges. ${ }^{2}$ However, certain difficulties have been reported with these conventional modes of treatment. For instance, removable prosthesis is most often associated with lack of retention and stability which will have an adverse effect on mastication as well as speech. Impaired taste sensation, accumulation of food debris and plaque leading to poor oral hygiene have also been reported. This will eventually affect the patient's self confidence in social gatherings. When it comes to fixed partial denture, the abutment teeth are prepared for retainers because of which the adjacent healthy teeth are compromised. Iatrogenic factors like faulty preparation of the gingival margins can lead to recurrent gingivitis. Therefore, there is a need for better treatment options. ${ }^{2}$

With the advance in technology, dental implants have become a well-established and widely accepted treatment modality for rehabilitation of completely and partially edentulous jaws. ${ }^{1}$ Implant supported prosthesis provide greater stability, improved retention, masticatory efficiency and higher patient satisfaction. ${ }^{3}$ The high success rate and predictability of implants have increased their clinical implication. However, the outlook of the general population towards implant therapy are less known. ${ }^{4}$ The lack of knowledge and affordability has limited the use of implant supported prosthesis. ${ }^{3}$

The information available to the patients regarding implant procedure and its success is often fragmentary. This issue is more severe in developing countries where enough measures are not being taken to educate and spread awareness about implants being a superior dental treatment modality. Lack of adequate communication can lead to a negative attitude towards implant therapy which can be eliminated by providing the right information to the patients. Channelizing the right information in the right way to the patient can help in promoting implant therapy as a superior treatment option. Therefore, it is important for clinicians to know whether the patients have right information regarding the implant procedure. 5

Information regarding the use of dental implant can be obtained by various means like television, journals, friends, internet, advertisements etc. but some studies have shown that the most reliable source of information is undoubtedly dentist. Dentist can give information as well as create awareness regarding the use of dental implants and can easily solve the questions or query of the patient regarding the dental implants. ${ }^{4}$

As implant therapy is an elective procedure in most of the scenarios, it is essential to guide the patients to make the most appropriate choice of treatment by providing complete information on implant therapy and alternative treatment options. Limited study exists on assessing the knowledge and awareness regarding the use of dental implants among the general population. ${ }^{3}$ Due to its increased popularity among dental surgeons, it is essential to assess the level of awareness among the general population. Hence, this study was conducted in a dental setting to assess the awareness and acceptance of implant treatment as an option to replace missing teeth amongst the patient seeking for prosthodontic rehabilitation.

\section{METHODS}

A cross-sectional survey was conducted among the patients visiting the outpatient Department of Prosthodontics Crown \& Bridge in A.B. Shetty Memorial Institute of Dental Sciences, Nitte, (Deemed to Be University), Mangalore, Karnataka. Study duration was from May 2017 to May 2018. Informed consent from each participant was obtained to participate in the study and to use the data for the purpose of research. Ethical clearance was obtained from Institutional ethical committee (ABSM / EC / 65 / 2020) Nitte (Deemed to Be University), for the execution of the study. Random sampling method with a convenient sample was taken. A total of 100 patients above the age of 16 seeking for any prosthodontic rehabilitation were selected for the study. The data was collected in the form of a questionnaire which was similar to the one used by previous researchers. ${ }^{3,5}$ A structured questionnaire comprising of 20 questions with multiple choices that included questions to determine the knowledge, source of knowledge, the attitude of patients towards implants treatment and other relevant points were distributed by a single examiner to the participants who voluntarily agreed to participate in the study. The content of the questionnaire was read out and explained in the local language and participants were asked to fill the multiplechoice questionnaire.

\section{Statistical Analysis}

Descriptive statistics were generated to summarise the response.

\section{RESULTS}

The results were analysed based on the collective response of each amongst 100 patients summarised in the form of tables (Table 1 and 2) and pie charts (Graph 1 - 3).

Among 100 patients, $48 \%$ were females and $52 \%$ were males out of which $43.9 \%$ belonged to the age group of $41-60$ and $30.6 \%$ belonged to the age group of $21-40$. (Table 1 ) The results showed that $73.2 \%$ of the patients visited the dentist only at the time of requirement and $16.5 \%$ and $10.3 \%$ visited once in a year and once in 6 months, respectively. $60.4 \%$ of the patients presented with some form of dental prosthesis and $71.1 \%$ of the patients were unhappy with a removable prosthesis.

\begin{tabular}{|c|c|c|}
\hline Factor & Categories & Percentage (\%) \\
\hline \multirow{2}{*}{ Gender } & Male & $48 \%$ \\
& Female & $52 \%$ \\
& $16-20$ years & $7 \%$ \\
\multirow{2}{*}{ Age } & $21-40$ years & $30.6 \%$ \\
& $41-60$ years & $43.9 \%$ \\
& $61-80$ years & $18.4 \%$ \\
\hline \multicolumn{2}{|c|}{ Table 1. Gender and Age Distribution } \\
\hline \multicolumn{3}{c}{} \\
\hline
\end{tabular}


It was found that $51 \%$ of the patients were not aware of implant therapy as a treatment option for replacing missing teeth while $44.9 \%$ were aware of implant therapy. (Graph 1)
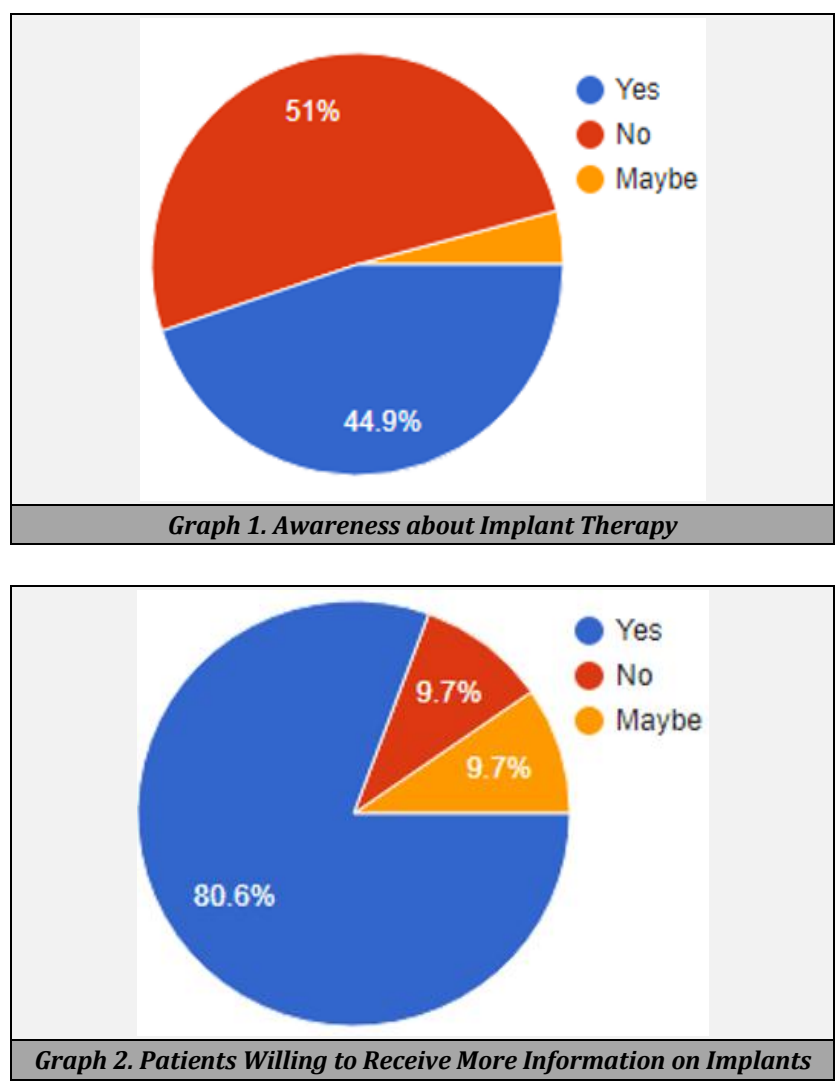

Regarding the source of information, $38 \%$ of the patients received information about implants from dentist and $38 \%$ of them received from books / magazine / internet. (Table 2) $80.6 \%$ of the patients showed a positive attitude and were interested in knowing more about implant therapy. (Graph 2) $53.6 \%$ of the patients had no idea where in the oral cavity implants are placed and $38.1 \%$ had an idea about the implant being placed in the jawbone. (Table 2)

\begin{tabular}{|c|c|c|}
\hline Factor & Categories & Percentage $(\%)$ \\
\hline \multirow{4}{*}{$\begin{array}{l}\text { Knowledge about implants } \\
\text { (placement of implants) }\end{array}$} & In the jawbone & $38.1 \%$ \\
\hline & In the gums & $8.3 \%$ \\
\hline & On the neighbouring tooth & - \\
\hline & I do not know & $53.6 \%$ \\
\hline \multirow{3}{*}{$\begin{array}{l}\text { Source of information about } \\
\text { implants }\end{array}$} & From your dentist & $38 \%$ \\
\hline & Books / magazines / internet & $38 \%$ \\
\hline & $\begin{array}{c}\text { From someone who has already } \\
\text { undergone this treatment }\end{array}$ & $24 \%$ \\
\hline \multirow{2}{*}{ Treatment charges } & Affordable & $41.2 \%$ \\
\hline & Non-affordable & $58.8 \%$ \\
\hline $\begin{array}{l}\text { Table 2. Knowledge } \\
\text { Source of Informatic }\end{array}$ & $\begin{array}{l}\text { about Implants (Placement } \\
\text { about Implants and Treat }\end{array}$ & $\begin{array}{l}\text { of Implants), } \\
\text { ment Charges }\end{array}$ \\
\hline
\end{tabular}

$58.8 \%$ of the patients rated implant treatment as not affordable and $41.2 \%$ rated it as affordable (Table 2). $44.3 \%$ of the patients were willing to undergo implant therapy as a treatment option if needed but $25.8 \%$ of the patients were not willing and $29.9 \%$ of them were open to the idea of implants but were not sure.

The most common reason listed for not opting implant treatment was found be the cost of the treatment $45.1 \% .27 .5$ $\%$ of the patients were not clear about the procedure and 11.8
$\%$ of them stated long treatment time as the disadvantage of implant therapy. (Graph 3)

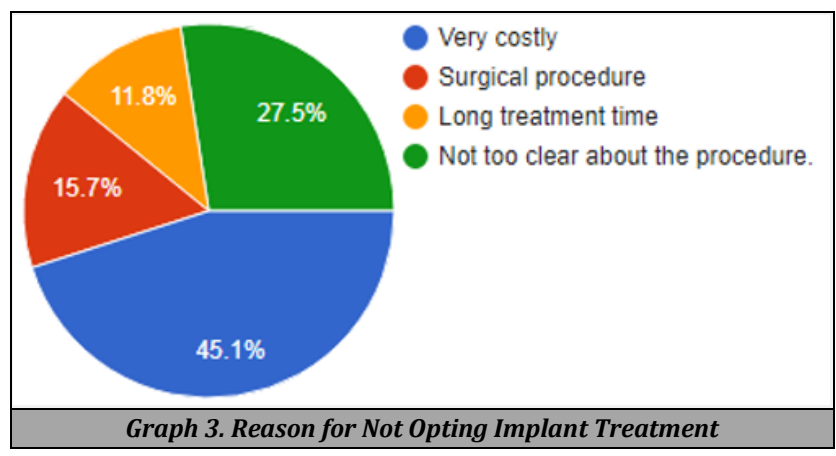

\section{DISCUSSION}

Tooth loss can be either due to oral disorders such as caries, gingival and osseous disease, or other reasons as well, such as accidents and iatrogenic procedures. It can affect the apparent status of person as well as their confidence. ${ }^{6}$ Dentures and fixed bridges are the most commonly preferred methods to rehabilitate edentulous conditions. However, due to several anatomical, physiological, psychological, and prosthodontic factors such as limited retention and stability, predominantly in the mandibular arches, the acceptance rate of traditional removable dentures has reduced considerably. ${ }^{6}$ Dental implant is an artificial tooth root fixed into the jaws to hold a replacement tooth or bridge. Implant retained prosthesis provides greater stability, improved biting and chewing forces and higher patient satisfaction than a conventional denture. ${ }^{3}$

Dental implants have become the norm of today's prosthetic and restorative dentistry. Various studies have showed dental implants to be a satisfactory replacement due to its excellent biocompatible nature. ${ }^{3}$ The level of awareness towards implant therapy needs to be improved so that patients can decide the most appropriate treatment modality. Due to the lack of education and awareness in the developing countries, this problem becomes more magnified. Numerous studies conducted in different countries have shown varied level of awareness and perception about dental implant treatment. 6

Information regarding the use of dental implant can be obtained by various means like television, journals, friends, internet, advertisements etc. but some studies have shown that the most reliable source of information is undoubtedly dentist. Dental surgeons can play a vital role in educating the patients about various treatment options provided in the dental clinics. ${ }^{2}$

A survey conducted by Zimmer et al. showed high acceptance rate among the public and a positive attitude was observed toward dental implants. ${ }^{7}$ A similar survey by Tepper et al. 2003, reported the level of awareness about dental implant procedure to be $72 \%$, and $42 \%$ of them said they were not informed at all about dental implants, whereas only $4 \%$ said they were well informed about dental implants. ${ }^{8}$

In the present survey, when asked about the frequency of dental visits, $73.2 \%$ of the patients visited the dentist only at the time of requirement and the most common reason for their visit was to replace missing tooth / teeth. 
Majority of the patients (60.8\%) were aware of the various treatment options present to replace missing teeth. When comparing the removable and fixed prosthesis, $71.1 \%$ of the patients were not content with a removable prosthesis. Satpathy et al. found in their survey that majority (71.24\%) of the patients were not satisfied with a removable prosthesis for replacing missing teeth which confirms the fact that the patients preferred fixed over removable prosthesis irrespective of their clinical situation. ${ }^{5}$ This result was in accordance with those concluded by Tepper et al. ${ }^{8}$ Zimmer et al. ${ }^{7}$ and Pommer et al. ${ }^{9}$

In the current study, only $44.9 \%$ of patients were aware of implant as the treatment option for replacing missing teeth. However, the findings were lower than studies conducted by Zimmer et al. (1992), Berge, (2000), and Tepper et al. (2003) which reported the level of awareness as $77 \%, 70.1 \%$ and 72 $\%$, respectively. ${ }^{6}$

Regarding the source of information, $38 \%$ of the patients received information from dental professionals and $38 \%$ received information from books / magazines / internet. Studies by Tepper et al. (2003),10 Pommer et al. (2010), showed that $68 \%$ and $74 \%$ of patients respectively received the primary information about implants from dental surgeons. Although other studies by Berge, Best and Zimmer et al. reported media to be the main source of information. ${ }^{3}$

When questions regarding the placement of implants were asked $53.6 \%$ of the patients were not aware of the area where the implants are placed and $38.1 \%$ had an idea about the implant being placed in the jawbone. $44.3 \%$ of the patients showed a positive attitude towards implant therapy and were willing to undergo the treatment if required. On the other hand, $25.8 \%$ of the patients were not willing for implant therapy and the main reason listed was the cost (45.1\%) of the treatment followed by the surgical procedure involved. Kumar et al. ${ }^{3}$ in their survey found that majority ( $70 \%$ ) of the patients reported high cost of implants as a major barrier in their use.

This survey points out the lack of awareness among patients about implant treatment and reduced patient acceptance because of the high cost of this treatment modality. However, the study conducted included majority of the population with a lower literacy level and a low socioeconomic status which resulted in lack of acceptance and lack of awareness among them. Hence, further studies including the general population should be conducted to evaluate the awareness about dental implants.

Hence, every dental professional in their clinical practice should encourage and educate patients about dental implant treatment being a successful treatment modality to replace missing teeth.

\section{CONCLUSIONS}

In conclusion, $44.9 \%$ of the patients were aware of the implant therapy as a treatment option to replace missing teeth and
$44.3 \%$ showed a positive attitude towards implant therapy and were willing to undergo the treatment if required.

However, there is a need for further studies including the general population as most of the patients in this study were from a low socio-economic background.

Data sharing statement provided by the authors is available with the full text of this article at jemds.com.

Financial or other competing interests: None.

Disclosure forms provided by the authors are available with the full text of this article at jemds.com.

\section{REFERENCES}

[1] Chaudhary S, Gowda TM, Kumar TAB, et al. Knowledge and attitudes of dental interns in Karnataka state, India, regarding implants. J Dent Educ 2013;77(10):1365-70.

[2] Mgbeokwere U, Okoye L, Ekwueme 0. A survey of the knowledge of dental implants as a choice in treatment of edentulous jaws among health workers in Government Dental Clinics in Enugu. Ann Med Health Sci Res 2011;1(1):91-6

[3] Kumar S, Chauhan A. Knowledge and awareness of dental implants in Indore: an exploratory study. Int J Oral Med Sci 2015;2(4):29-33.

[4] Kohli S, Bhatia S, Kaur A, et al. Patients awareness and attitude towards dental implants. Indian J Dent 2015;6(4):167-71.

[5] Satpathy A, Porwal A, Bhattacharya A, et al. Patient awareness, acceptance and perceived cost of dental implants as a treatment modality for replacement of missing teeth: a survey in Bhubaneswar and Cuttack. International Journal of Public Health Dentistry 2011;2(1):1-7.

[6] Alqahtani F, Alqahtani H, Alshalwi A, et al. Patients awareness of a dental implant as an option for tooth replacement: a survey in Alkharj Province, Saudi Arabia. Int J Dent Oral Health 2015;1(3):1-4.

[7] Zimmer CM, Zimmer WM, Williams J, et al. Public awareness and acceptance of dental implants. Int J Oral Maxillofac Implants 1992;7(2):228-32.

[8] Tepper G, Haas R, Mailath G, et al. Representative marketing-oriented study on implants in the Austrian population. I. Level of information, sources of information and need for patient information. Clin Oral Implants Res 2003;14(5):621-33.

[9] Pommer B, Zechner W, Watzak G, et al. Progress and trends in patients' mindset on dental implants. I: level of information, sources of information and need for patient information. Clin Oral Implants Res 2011;22(2):223-9.

[10] Shirmohammadi M, Faramarzi M, Chisazi MT, et al. Patient's knowledge regarding dental implants in Tabriz, Iran. Avicenna J Dent Res 2013;4(1):43-8. 